\title{
Kuopio birth cohort - design of a Finnish joint research effort for identification of environmental and lifestyle risk factors for the wellbeing of the mother and the newborn child
}

Pasi Huuskonen', Leea Keski-Nisula², Seppo Heinonen ${ }^{2,3}$, Sari Voutilainen ${ }^{4}$, Tomi-Pekka Tuomainen ${ }^{4}$, Juha Pekkanen ${ }^{5,6}$, Jussi Lampi ${ }^{6}$, Soili M Lehto ${ }^{7,8}$, Hannariikka Haaparanta', Antti-Pekka Elomaa9 Raimo Voutilainen ${ }^{10}$, Katri Backman ${ }^{10}$, Hannu Kokki ${ }^{11}$, Kirsti Kumpulainen ${ }^{12}$, Jussi Paananen ${ }^{13}$, Kirsi Vähäkangas ${ }^{1}$ and Markku Pasanen ${ }^{{ }^{*}}$ (D)

\begin{abstract}
Background: A Finnish joint research effort Kuopio Birth Cohort (KuBiCo) seeks to evaluate the effects of genetics, epigenetics and different risk factors (medication, nutrition, lifestyle factors and environmental aspects) during pregnancy on the somatic and psychological health status of the mother and the child.

Methods: KuBiCo will ultimately include information on 10,000 mother-child pairs who have given their informed consent to participate in this cohort. Identification of foetal health risk factors that can potentially later manifest as disease requires a repository of relevant biological samples and a flexible open up-to-date data handling system to register, store and analyse biological, clinical and questionnaire-based data. KuBiCo includes coded questionnairebased maternal background data gathered before, during and after the pregnancy and bio-banking of maternal and foetal samples that will be stored in deep freezers. Data from the questionnaires and biological samples will be collected into one electronic database. KuBiCo consists of several work packages which are complementary to each other: Maternal, foetal and placental metabolism and omics; Paediatrics; Mental wellbeing; Prenatal period and delivery; Analgesics and anaesthetics during peripartum period; Environmental effects; Nutrition; and Research ethics.
\end{abstract}

Discussion: This report describes the set-up of the KuBiCo and descriptive analysis from 3532 parturients on response frequencies and feedback to KuBiCo questionnaires gathered from June 2012 to April 2016. Additionally, we describe basic demographic data of the participants $(n=1172)$. Based on the comparison of demographic data between official national statistics and our descriptive analysis, KuBiCo represents a cross-section of Finnish pregnant women.

Keywords: Birth weight, Environmental health, Foetus, Maternal smoking, Mental health, Metabolism, Nutrition, Paediatrics, Placenta, Research ethics

\footnotetext{
* Correspondence: markku.pasanen@uef.fi

'School of Pharmacy, Faculty of Health Sciences, University of Eastern

Finland, P.O. Box 1627, FI-70211 Kuopio, Finland

Full list of author information is available at the end of the article
}

(c) The Author(s). 2018 Open Access This article is distributed under the terms of the Creative Commons Attribution 4.0 International License (http://creativecommons.org/licenses/by/4.0/), which permits unrestricted use, distribution, and reproduction in any medium, provided you give appropriate credit to the original author(s) and the source, provide a link to the Creative Commons license, and indicate if changes were made. The Creative Commons Public Domain Dedication waiver (http://creativecommons.org/publicdomain/zero/1.0/) applies to the data made available in this article, unless otherwise stated. 


\section{Background}

Population-based pregnancy cohorts have demonstrated that foetal growth, exposure to smoking and pollutants as well as the presence of maternal diseases, the domestic environment, psychological stress and nutrition have long-term effects on the health of the offspring $[1,2]$. One way to investigate the multiple associations between the effects of prenatal exposure and health of the offspring later in life is via birth cohorts that combine clinical, questionnaire and biological data in a way that is easy to link. According to the Declaration of Helsinki (www.wma.net) and legislation in many countries including Finland (488/1999; www.finlex.fi), research ethics in human studies requires special attention. However, how to carry out practical procedures in cohort studies in ethically best way is not self-evident and requires further studies [3].

Human foetus is much more sensitive than adult to the adverse effects of chemicals or other risk factors. This is due to the on-going development, characterized by high cell proliferation capacity combined with deficiencies in the foetal metabolic detoxification capacity, an immature immune system and still-developing DNA-repair mechanisms [4]. At this stage, chemicals can permanently reprogram physiological responses through epigenetic mechanisms increasing the susceptibility of the foetus to diseases appearing after birth [5]. These modifications can be analysed, for instance, by RNA sequencing, metabolomics, proteomics and epigenetics [6-8]. In addition, it has also been demonstrated that maternal health status during pregnancy predicts future wellbeing of the child and mother [9].

Alterations occurring during the pre-, peri- and postnatal developmental periods can increase sensitivity for further aberrations at later stages of life [10]. Human data supporting this hypothesis emerges from studies showing that aberrant programming of growth and development can lead to respiratory disease [11], non-Hodgkin lymphoma [12] and neurological diseases [13].

In Finland, approximately 50\% of pregnant women consume medicinal products during their pregnancy [14]. In addition to medicinal products, natural and herbal medications are frequently used during pregnancy, and should be considered as a possible foetal risk factor [15]. Furthermore, up to $15 \%$ of pregnant women smoke in Finland [16]. There is a paucity of data concerning various maternal exposures during pregnancy and their impact on overall developmental outcomes.

Nutrients and their metabolism play a crucial role in the health and wellbeing of both mother and foetus, and they are associated with the long-term health of the offspring [17]. Less information exists about the intake of non-essential nutrients and other food-based compounds and about their association with the health of children.
Kuopio Birth Cohort (KuBiCo, www.kubico.fi) is anchored on the concept of developmental origin of diseases [18-20]. It will generate new knowledge by integrating clinical and analytical data, achieving a systematic increase in understanding the combined effects of multiple factors on health and disease. $\mathrm{KuBiCo}$ is intended to help resolve the effects of genetic and epigenetic backgrounds and potential risk factors (medications and nutritional, lifestyle, and environmental factors) during pregnancy on the health status of the mother and child. KuBiCo is a joint research effort between the University of Eastern Finland (UEF), the Kuopio University Hospital (KUH) and the National Institute for Health and Welfare (THL).

This paper describes the setup of $\mathrm{KuBiCo}$ and descriptive analysis of response frequencies and feedback to $\mathrm{KuBiCo}$ questionnaires of altogether 3532 parturients from June 2012 to April 2016. Additionally, we report basic demographic data of $1172 \mathrm{KuBiCo}$ participants and show that they agree with Finnish national statistics.

\section{Methods/design}

Altogether, the final database is planned to include 10,000 mother-child pairs. All pregnant women who are expected to give birth in KUH in the Finnish county Northern Savo are invited to participate in $\mathrm{KuBiCo}$. $\mathrm{KuBiCo}$ does not include individual exclusion criteria. Those who sign the informed consent at any stage of pregnancy will be included in $\mathrm{KuBiCo}$ and prospective data collection. Majority of the participants (>90\%) are recruited during the routine first trimester visit (gestational week 6-9) at the prenatal clinics by primary health care personnel or midwifes, when the pregnancy has been determined by clinical inspection.

\section{Collection and organization of data and samples}

Barcode identification stickers with a $\mathrm{KuBiCo}$ code are used to process samples into the system and archive all biological samples (maternal and umbilical cord blood, placental samples, microbial swab from neonate's oral cavity, hair and house dust samples) (Fig. 1). The groups participating in $\mathrm{KuBiCo}$ will utilize the WebKuBiCo database that sends, receives and stores all the questionnaire data from the beginning of the confirmed pregnancy until the child reaches adulthood. Each woman is entered into the WebKuBiCo database by using her personal bank account safety codes (the most widely used electronic identification system in Finland) and each pregnancy will have a $\mathrm{KuBiCo}$ code of its own. Therefore, during the project, one woman may have several $\mathrm{KuBiCo}$ codes in relation to subsequent pregnancies. This web-based platform will also automatically create educative/guiding feedback to the women based on their answers to the questionnaires. So far, the service has 


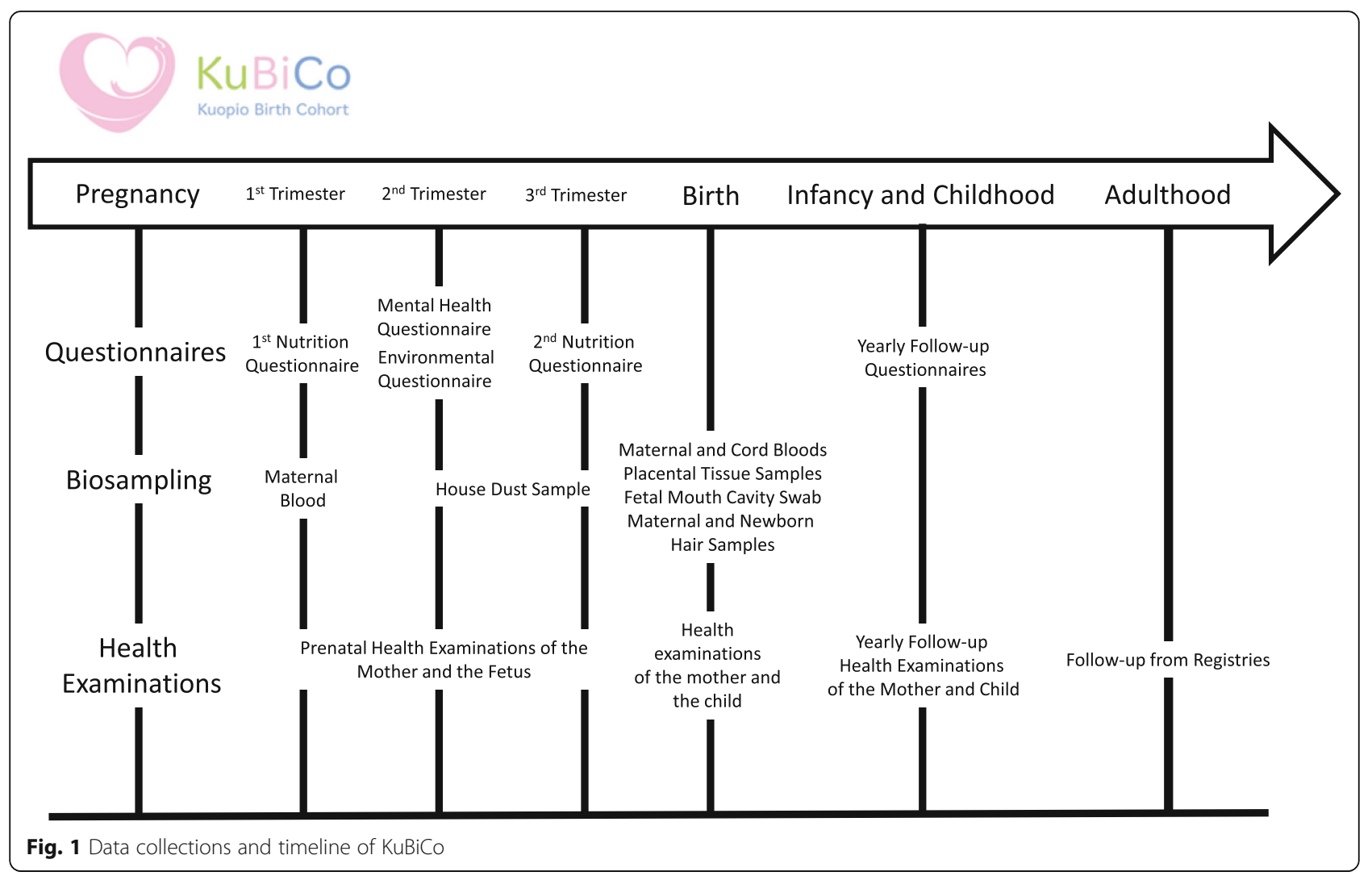

been developed for mental health and nutrition questionnaires. An outline of the $\mathrm{KuBiCo}$ is presented in Fig. 2.

Biological samples (maternal and umbilical cord blood, placental tissue sample, microbial swab from neonate's oral cavity, maternal and foetal hair samples) are collected by staff in KUH and the main management of samples is conducted by personnel of UEF. House dust samples are collected by the participating families according to THL instructions. Biological samples are stored in deep-freezers $\left(-80{ }^{\circ} \mathrm{C}\right)$ of $\mathrm{KUH}, \mathrm{UEF}$, and THL. House dust samples are stored and managed in the THL facilities.

All raw data from the questionnaires and biological samples will be collected and stored in an electronic $\mathrm{KuBiCo}$ database (eKuTKa) from which data can be downloaded for investigation by all research partners and international collaborators after mutual agreements. The KuBiCo advisory board grants permissions of $\mathrm{KuBiCo}$ data usage for research groups. This database will be developed and maintained by ISTEKKI (Information Technology services of KUH). The Bioinformatics unit at the UEF provides the appropriate bioinformatics software licenses, such as Revolution R Enterprise and Ingenuity Pathway Analysis (IPA). All raw data obtained from our own or any collaborative studies will be stored on the eKuTKa database and analysed by the core facilities. This will ensure continuous support for high quality research.

Data collected in the work packages is stored in centralized data servers. These consist of raw data, pre-processed data, and selected results from data analysis. Central storage and processing enables efficient curation, harmonization and integration of the data, resulting in high quality databank that can be reliably used for a wide range of research purposes. The data is version controlled and backed up, ensuring efficient storage and re-use. Access to specific parts of the data will be controlled, allowing for functional and secure data sharing and dissemination between the research partners and the research community as a whole. Standard formats for handling data from different high-throughput technologies will be used, and such data will be submitted to open access databases, such as Gene Expression Omnibus (GEO), as required by scientific journals upon publication.

To ensure harmonization of the research protocols for the studies performed in the different work packages of the $\mathrm{KuBiCo}$, all active partners have approved final protocols. This will lead to standardized collection, handling and storage procedures of the biological samples by the research groups. This also applies to the questionnaires on intake of food and supplements, somatic and mental health, ethics and all developmental follow-ups. In order 


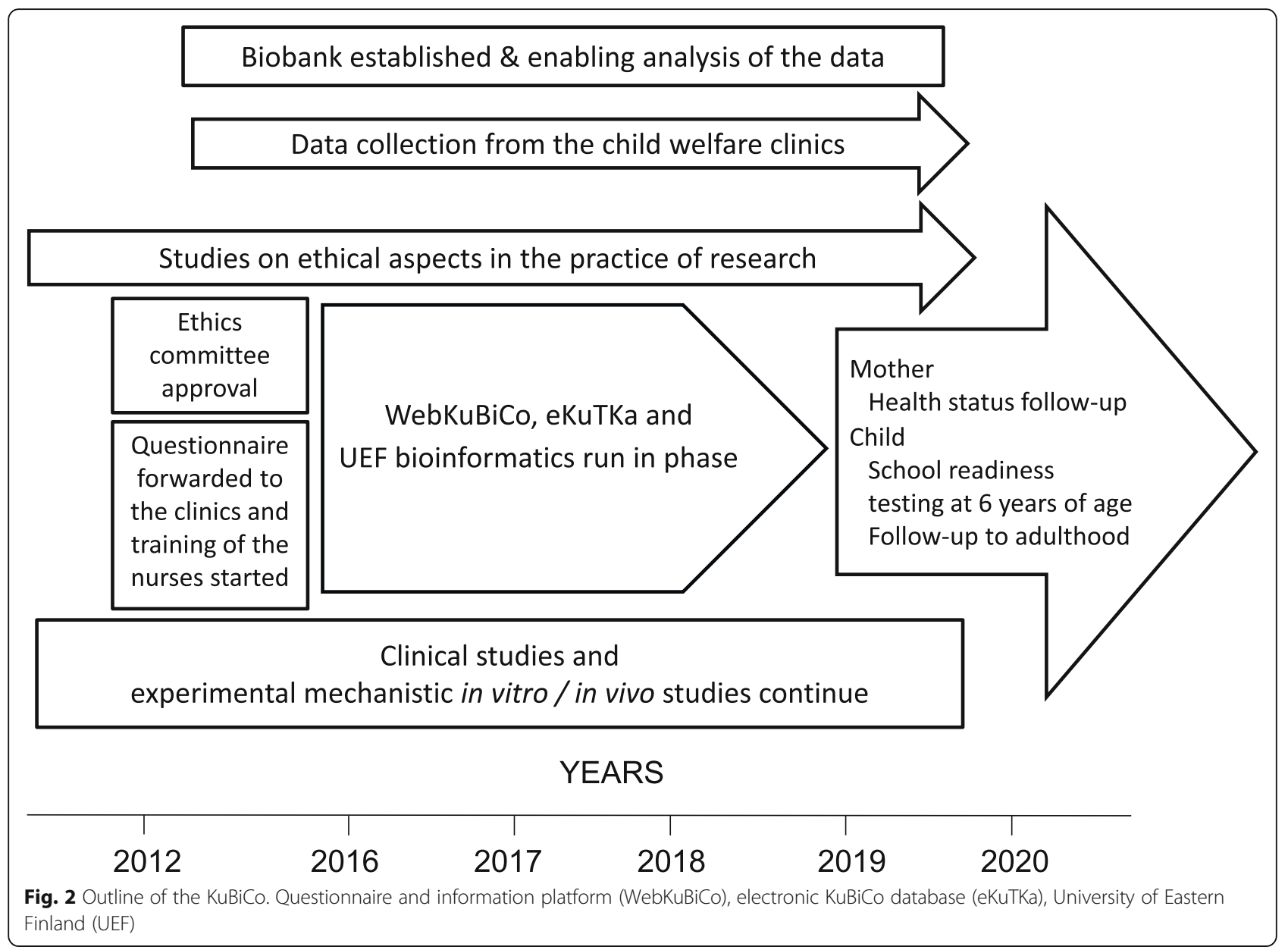

to facilitate planned future multinational collaborative research, all questionnaires are being translated into English from the original Finnish versions. By standardizing all the protocols and questionnaires, optimally robust and sufficiently powered statistical analyses will be achieved. Power calculations for the KuBiCo are conducted separately within each individual work package or research hypothesis using $\mathrm{KuBiCo}$ data. In addition, any missing data is handled separately in each $\mathrm{KuBiCo}$ work package. During study and after completion of the material collection the KuBiCo database can be linked to national health registries for epidemiological follow-ups.

\section{Research ethics}

The Research Ethics Committee of Hospital District of Central Finland in Jyväskylä, Finland has reviewed and approved the KuBiCo plan 15.11.2011. The ethical basis of $\mathrm{KuBiCo}$ is the expected major benefit for future research projects on developmental origin of various childhood and adult-onset diseases and the health of future generations. Data sharing among the participating research groups will make it possible to undertake large projects, and furthermore, all of the developed data will remain in the database for future generations of scientists. Pregnant women are asked to consider volunteer participation, which will involve that they provide their data and samples. In return, they are automatically informed about their nutritional or mental health status if any causes of concern are identified.

\section{Work packages within KuBiCo}

Metabolism and omics will study how different risk factors affect placental hormone production (i.e., potential for endocrine disruption) and xenobiotics metabolizing characteristics at different stages of pregnancy by the means of metabolic activity determination, genetics and epigenetics.

Paediatrics will survey the somatic health, growth and overall development of the children by annual questionnaires to elucidate the role of prenatal factors, for example maternal smoking and microbe exposure during birth, on health and morbidity of the offspring in later childhood, adolescence and adulthood.

Mental wellbeing targets associations between maternal psychological wellbeing and systemic biomarkers during pregnancy, and how the maternal mental wellbeing 
modulates neonate physiology and the child's later development. Furthermore, the psychological development and wellbeing of the child as well as parent-child relationships will be studied.

Prenatal period and delivery evaluate perinatal and genetic epidemiology, and risk factors and markers for most common obstetrical and perinatal complications, and how these factors affect the perinatal outcomes and later the child's subsequent health. Data is collected on different prenatal exposures by biological samples and questionnaires and linked to the information available on prenatal outcomes and the child's subsequent health.

Analgesics and anaesthetics during peripartum period evaluates the foetal and newborn effects of analgesics and anaesthetics given for parturient during the perinatal period. Maternal pharmacokinetics and -dynamics of different compounds used for pain relief and anaesthesia will be measured aimed at establishing a pharmacodynamic and -kinetic in silico model based on foetal and newborn exposures evaluated from venous blood.

Environment The studies on the effects of different environmental exposures are focused on environmental determinants of asthma and allergic diseases, especially of the exposure to the microbes in indoor air and air pollution, and of the environmental chemical exposure on the health and development of the offspring. Environmental exposures are assessed in $\mathrm{KuBiCo}$ with two separate comprehensive questionnaires during first and third trimesters. In addition, voluntary house dust samples are collected during first and third trimesters and neonatal mouth mucosa swab at birth. Also, maternal serum samples are collected for chemical analyses during first trimester and at birth, and umbilical cord blood samples at birth if clinically feasible (see Table 1).

Nutrition Intake of food and supplements are collected using food frequency questionnaire (FFQ) during the first and third trimester of pregnancy and dietary data of the children at 2 and 4 years of age. Web-based FFQ comprises a food list of about 160 food items with nine frequency response options from "never" to "six or more times per day". More than 60 nutrients and 100 food groups are provided. FFQ includes also specific questions about supplement use. KuBiCo FFQ has been further developed to produce personal feedback about nutrition at first and third trimester of pregnancy.

Research ethics $\mathrm{KuBiCo}$ provides a unique opportunity to pursue the following important points: 1) recruitment and informed consent in a birth cohort, 2) evaluation by the recruited families of the usefulness and potential risks to their families, 3) handling and long-term storage of samples and information for future use, 4) societal benefits of the type of information collected in $\mathrm{KuBiCo}$ and 5) what affects the decisions of the people approached for recruitment. One of the main aims is to develop reliable tools to evaluate ethical issues in birth cohort studies.

\section{Descriptive analysis of the KuBiCo database}

All material collected between June 2012 and April 2016, altogether 3532 maternal answers to the questionnaires were included in the descriptive analysis. Additionally, an analysis of demographic data of mother-child pairs was carried out. This included full background information and medical records containing 1172 pregnancies, which included 1156 single pregnancies and 16 twin pregnancies. The background information collected from the mothers included age, number of medications, diseases, smoking status, and use of alcohol during pregnancy. Information about pregnancies included the duration of the pregnancy and the weight of placenta. The newborn information included birthweight, gender and date of birth. The overall participation in KuBiCo during 2012-2016 (3532 women) has been $37.3 \%$ of all parturients giving birth in KUH. Table 1 describes the number of women who filled $\mathrm{KuBiCo}$ forms completely

Table 1 Number of participants answering KuBiCo questionnaires from June 2012 to April 2016

\begin{tabular}{|c|c|c|}
\hline \multirow[t]{3}{*}{ General data } & $\begin{array}{l}\text { Total number of participants (per cent of total number of parturients } \\
\text { at Kuopio University Hospital) }\end{array}$ & $3532(37.3 \%)$ \\
\hline & Number of children included in the follow-up study & 3187 \\
\hline & Women participating in KuBiCo for the second time & 230 \\
\hline \multirow[t]{8}{*}{ Number of women answering questionnaires of } & Ethics & 2635 \\
\hline & Environmental stress factors - first trimester/last trimester & $2464 / 2134$ \\
\hline & Nutrition up to gestation week 13/from gestation week 28 to delivery & $1625 / 3240$ \\
\hline & Mental health & 2658 \\
\hline & When the child was 12 months old & 1955 \\
\hline & When the child was 24 months old & 1477 \\
\hline & Nutrition when the child was 24 months old & 1402 \\
\hline & When the child was 36 months old & 480 \\
\hline Number of women collecting samples & Women who completed the collection of house dust & 630 \\
\hline
\end{tabular}


or partly and Table 2 the descriptive characteristics of the cohort.

Approximately one-fifth of the women had taken at least one regular medication during pregnancy (Table 3).
Regular medications were mainly related to the women's chronic diseases; thyroid diseases, asthma and mental health conditions which were the most frequent chronic diseases in pregnant women as expected (Table 4).

Table $\mathbf{2}$ Characteristics of the study population in relation to the gestational age at delivery

\begin{tabular}{|c|c|c|c|c|}
\hline & $\begin{array}{l}\text { Total newborn } \\
n=1172\end{array}$ & $\begin{array}{l}\text { Preterm birth } \\
<37 \text { GWS } \\
n=81(6.9)\end{array}$ & $\begin{array}{l}\text { Term birth } \\
37-40 \text { GWS } \\
n=855(73.0)\end{array}$ & $\begin{array}{l}\text { Late-term birth } \\
\geq 41 \text { GWS } \\
n=236(20.1)\end{array}$ \\
\hline Birth weight, g & $3446 \pm 597$ & $2156 \pm 704$ & $3497 \pm 470$ & $3701 \pm 395$ \\
\hline 1 st tertile $\leq 3280$ & & $79(20)$ & $218(56)$ & $94(24)$ \\
\hline 2nd tertile 3281-3700 & & $2(0.5)$ & $166(43)$ & $223(57)$ \\
\hline 3rd tertile $\geq 3701$ & & $0(0)$ & $131(34)$ & $259(66)$ \\
\hline Placental weight ${ }^{a}, g$ & $590 \pm 130$ & $439 \pm 117$ & $592 \pm 125$ & $620 \pm 124$ \\
\hline 1st tertile $\leq 530$ & & $51(13)$ & $179(47)$ & $155(40)$ \\
\hline 2nd tertile 531-630 & & $8(2.1)$ & $179(47)$ & $196(51)$ \\
\hline 3rd tertile $\geq 631$ & & $2(0.5)$ & $145(39)$ & $225(61)$ \\
\hline Maternal age ${ }^{b}$, years & $29.8 \pm 5.1$ & $30.7 \pm 5.4$ & $29.9 \pm 5.0$ & $29.4 \pm 5.3$ \\
\hline 1 st tertile $\leq 28$ & & $21(4.6)$ & $203(44)$ & $233(51)$ \\
\hline 2nd tertile 29-32 & & $28(7.4)$ & $161(43)$ & $188(50)$ \\
\hline 3rd tertile $\geq 33$ & & $22(6.8)$ & $145(45)$ & $155(48)$ \\
\hline Number of previous deliveries ${ }^{b}$ & $1.0 \pm 1.3$ & $0.7 \pm 1.1$ & $1.1 \pm 1.3$ & $0.7 \pm 1.1$ \\
\hline Nulliparous & & $45(8.8)$ & $210(41)$ & $258(50)$ \\
\hline Primiparous & & $14(3.9)$ & $159(44)$ & $186(52)$ \\
\hline Multiparous & & $12(4.2)$ & $140(49)$ & $132(47)$ \\
\hline Number of twin pregnancies & $16(1.4)$ & $10(63)$ & $6(38)$ & $0(0)$ \\
\hline Gestational week at delivery, weeks ${ }^{b}$ & $39.2 \pm 2.0$ & $33.5 \pm 3.2$ & $39.1 \pm 0.9$ & $41.1 \pm 0.3$ \\
\hline Foetal sex, males & $589(50.3)$ & $42(51.9)$ & $443(51.8)$ & $104(44.1)$ \\
\hline Self-reported smoking before pregnancy & $226(20)$ & & & \\
\hline \multicolumn{5}{|l|}{ Number of daily cigarettes before pregnancy ${ }^{b}$} \\
\hline No smoking & $957(80)$ & $60(6.3)$ & $715(75)$ & $182(19)$ \\
\hline $1-10$ & $135(11.7)$ & $4(3.0)$ & $93(69)$ & $38(28)$ \\
\hline$\geq 11$ & $64(5.5)$ & $7(11)$ & $41(64)$ & $16(25)$ \\
\hline Self-reported smoking during pregnancy & $49(4.2)$ & & & \\
\hline \multicolumn{5}{|l|}{ Number of daily cigarettes during pregnancy ${ }^{b}$} \\
\hline No smoking & $1104(96)$ & $68(6.2)$ & $811(74)$ & $225(20)$ \\
\hline $1-5$ & $28(2.4)$ & $1(3.6)$ & $22(79)$ & $5(18)$ \\
\hline$\geq 6$ & $24(2.1)$ & $2(8.3)$ & $16(67)$ & $6(25)$ \\
\hline \multicolumn{5}{|c|}{ Self-reported alcohol consumption before pregnancy ${ }^{\mathrm{b}}$, weekly doses (average) } \\
\hline None & $601(52)$ & $27(4.5)$ & $468(78)$ & $106(18)$ \\
\hline $1-5$ & $497(43)$ & $40(8.0)$ & $343(69)$ & $114(23)$ \\
\hline$\geq 6$ & $58(5.0)$ & $4(6.9)$ & $38(66)$ & $16(28)$ \\
\hline \multicolumn{5}{|c|}{ Self-reported alcohol consumption during pregnancy ${ }^{b}$, monthly (average) } \\
\hline Never & $1053(96)$ & $66(6.3)$ & $172(73)$ & $215(20)$ \\
\hline Less than once & $36(3.3)$ & $12(2.8)$ & $23(64)$ & $12(33)$ \\
\hline Once a month, and more & $11(1.0)$ & $1(9.1)$ & $9(82)$ & $1(9.1)$ \\
\hline
\end{tabular}

Values are $\mathrm{n}(\%)$ or mean $\pm \mathrm{SD}$

${ }^{a}$ Excluded twin pregnancies, $n=16$

${ }^{b}$ mothers with twin pregnancies included only once, total $n=1156$ gestational weeks (GWS) 
Table 3 Regular use of medication among 1156 women during pregnancy in relation to gestational age at delivery

\begin{tabular}{lllll}
\hline Amount of regular medication & $\begin{array}{l}\text { Total } \\
n=1156\end{array}$ & $\begin{array}{l}\text { Preterm birth } \\
<37 \mathrm{GWS} \\
n=71(6.1)\end{array}$ & $\begin{array}{l}\text { Term birth } \\
37-40 \mathrm{GWS} \\
n=849(73.4)\end{array}$ & $\begin{array}{l}\text { Late-term birth } \\
\geq 41 \text { GWS } \\
n=236(20.4)\end{array}$ \\
\hline No regular medication & & $52(6)$ & $683(74)$ & $193(21)$ \\
Regular medication & $928(80)$ & $19(8)$ & $96(73)$ & $43(19)$ \\
1 medication & $228(20)$ & $9(7)$ & $89(72)$ & $26(21)$ \\
2 medications & $124(11)$ & $6(10)$ & $39(72)$ & $26(18)$ \\
$\quad 3$ medications & $60(5)$ & $4(9)$ & $34)$ & $6(14)$ \\
\hline
\end{tabular}

Values are $n$ (\%) of all parturients. Gestational weeks (GWS)

\section{Discussion}

The organization of the KuBiCo is unique by enabling linkage of birth cohort biobank with clinical follow-up and thus creating the possibility to tackle various questions within the developmental origin of disease concept.

One of the advantages of the $\mathrm{KuBiCo}$ is that the Finnish primary health care system routinely monitors the pregnant women and children and records their medical history. The other advantage of $\mathrm{KuBiCo}$ is that all of the questionnaires are in an electronic format, and can be filled in whenever convenient for the participant. Every pregnant woman will receive her personal Web$\mathrm{KuBiCo}$ password that allows her to fill in the form and to follow the progress of the project. Additionally, some of the questionnaires (mental health and nutrition) include automatic feedback to the participant about their present health status highlighting "safety phrases" if certain threshold scores are exceeded. These thresholds are based on established clinical cut-offs [21] and nutritional guidelines [17]. The aim of this feedback was to motivate and provide an additional health benefit for the participating pregnant women, and they have reported that the feedback has been helpful. Therefore, the developed feedback service is already included into the daily routines in the clinics.

To identify selection bias, a descriptive analysis was performed for 1172 participants of KuBiCo. We found out that $\mathrm{KuBiCo}$ corresponds well with the general pattern of Finnish pregnancies and deliveries. In the descriptive analysis (2012-2014), 6.9\% of the deliveries were preterm ( $<37$ weeks), 73\% full-term (37-40 weeks) and $20.1 \%$ late-term ( $\geq 41$ weeks). In 2015 , the corresponding nationwide Finnish delivery statistics were $5.9 \%$ preterm, $71.4 \%$ full-term and $22.5 \%$ late-term deliveries [16]. Mean maternal age in $\mathrm{KuBiCo}$ was $29.8 \pm$ 5.1 years and the Finnish average 30.6 years in 2015 . The Finnish mean maternal age has increased by 1.5 years from the $1990 \mathrm{~s}$, including older primiparas and increased numbers of over 35-year old women [16].

The mean birth weight in this descriptive analysis was $3446 \pm 597 \mathrm{~g}(n=1172)$ which is similar to the Finnish mean birthweight i.e. $3485 \mathrm{~g}$ in 2015 [16]. Compared to other Scandinavian countries, the decrease of mean birthweight has been more significant in Finland since the 1990s. This decrease of mean birthweight is especially apparent in boys and in macrosomic foetuses. The reason for this phenomenon is unknown and a potential subject for further investigations within and between cohorts.

There were 16 twin pregnancies in this descriptive analysis (1.4\% of 1156 deliveries) which is equivalent to the Finnish overall rate of multiple births (13.6/1000 deliveries in 2014) [22]. The twinning rate in Finland is low when compared to European median twinning rate,

Table 4 Women with specific chronic diseases with regular prescription medications initiated before pregnancy in relation to the gestational age at delivery

\begin{tabular}{|c|c|c|c|c|}
\hline & $\begin{array}{l}\text { Total } \\
n=1156\end{array}$ & $\begin{array}{l}\text { Preterm birth } \\
<37 \text { GWS } \\
n=71(6.1)\end{array}$ & $\begin{array}{l}\text { Term birth } \\
37-40 \text { GWS } \\
n=849(73.4)\end{array}$ & $\begin{array}{l}\text { Late-term birth } \\
\geq 41 \text { GWS } \\
n=236(20.4)\end{array}$ \\
\hline No regular medication & $928(80)$ & $52(6)$ & $683(74)$ & $193(21)$ \\
\hline Thyroid diseases & $96(8)$ & $7(7)$ & $71(74)$ & $18(19)$ \\
\hline Asthma & $60(5)$ & $6(10)$ & $43(72)$ & $11(18)$ \\
\hline Mental health conditions & $45(4)$ & $4(9)$ & $32(71)$ & $9(20)$ \\
\hline Neurological diseases & $7(0.6)$ & $1(14)$ & $2(29)$ & $4(58)$ \\
\hline Diabetes & $10(0.9)$ & $3(30)$ & $7(70)$ & 0 \\
\hline Inflammatory bowel diseases & $13(1)$ & 0 & $10(77)$ & $3(23)$ \\
\hline Hypertension & $13(1)$ & $5(39)$ & $8(62)$ & 0 \\
\hline
\end{tabular}

Values are $n(\%)$ of all parturients. Gestational weeks (GWS) 
which was $16.8 \%$ in 2010 [23]. Twin pregnancies carry higher risks of adverse foetal and neonatal outcomes such as higher rates of preterm birth, perinatal mortality and in the longer-term neuro-developmental impairments [23]. In this analysis, ten out of the sixteen twins $(62.5 \%)$ were preterm. One reason for the lower rate of twin pregnancies in Finland may be due to the recommendations of one-embryo transfers in infertility treatment programs.

The gender percentages of the newborns in KuBiCo were $49.7 \%$ girls and $50.3 \%$ boys $(n=1172)$. Based on the official statistics in Finland, there have been more boys than girls since 1761 at least until 2015. In the past twenty years, the proportion of boys has varied between $50.9-51.4 \%$ in Finland. In 2015, a total of 55,759 children were born in Finland, and there were 1.3\% more boys than girls [16]. However, sex ratio changes have been reported from Spain [24], Scotland [25] and USA [26]. In this descriptive analysis, in the group of late-term births, the percentage of boys (44.1\%) was lower compared to girls. This signal will need to be confirmed in the future analyses.

During 1996-2010 in Finland, it was reported that nearly every second pregnant woman (46.9\%) purchased at least one prescription medication during any trimester of her pregnancy [14]. In our questionnaire-based data, $20 \%$ of women had used at least one regular prescription medication during pregnancy. It has been shown that some medications, such as anti-epileptics and antidepressants, may increase the risk for preterm birth and lower birthweight [27]. Lahesmaa-Korpinen and colleagues [14] observed that perinatal risks were more frequent when pregnant women are exposed to any pharmaceuticals during pregnancy. In the same study, the pregnant women who used medications had a $13 \%$ higher risk to have a small for gestational age newborn, a $27 \%$ higher risk to have a large for gestational age newborn and a $20 \%$ higher risk for preterm delivery in comparison with those women with no medications. In accordance with this proposal, we noted that preterm delivery was more frequent among the women with regular medication. However, it should be also stated that most of the women with regular medication delivered at term or post-term.

Cigarette smoking and use of alcohol are obviously the most frequent underestimated, but well recognized, confounding health factors. Fortunately, smoking during pregnancy in Finland is decreasing. In 2012, 17\% of pregnant women smoked during pregnancy, but the percentage is decreasing [22]. In $\mathrm{KuBiCo}$, only about $4 \%$ of the pregnant women reported smoking during pregnancy. However, when their smoking status was checked by serum cotinine determination in a subset, $8.5 \%$ had cotinine in amounts indicating smoking that is comparable to the levels reported previously [22]. Obviously, the present numbers are affected by the selection bias created by e.g. motivation and nicotine replacement therapy. In KuBiCo placental xenobiotic and steroid metabolizing enzymatic analysis in vitro [6,7], confirms the induction of cytochrome P450 1A1 (CYP1A1) by smoking.

Based on the comparison of demographic data between official national statistics and our descriptive analysis, KuBiCo cohort represents a cross-section of Finnish pregnant women. KuBiCo is a multidisciplinary collaborative effort that enables to unravel the effects of genetics, epigenetics and complex life style factors on the future health status of both mother and child. The $\mathrm{KuBiCo}$ is equipped with a digital database (eKuTKa) to serve all contributors; pregnant women can sign in, they can follow the progress and receive feedback from their questionnaires; it also permits the registered investigators' access the generated data. In its final form, the database will include the data from 10,000 mother-child pairs. Our descriptive analysis demonstrates that the material and the proposed confirmatory measures, for example smoking status verification, will guarantee the reliability and high quality of this cohort so that it can be exploited in future projects and analyses.

\section{Abbreviations \\ eKUTKa: electronic Kuopio Birth Cohort database; FFQ: Food frequency questionnaire; GEO: Gene Expression Omnibus; GWS: Gestational weeks; IPA: Ingenuity Pathway Analysis; ISTEKKI: Information Technology services of $\mathrm{KUH}$; KuBiCo: Kuopio Birth Cohort; KUH: Kuopio University Hospital; THL: National Institute for Health and Welfare; UEF: University of Eastern Finland; WebKuBiCo: Questionnaire and information platform}

\section{Acknowledgments}

The authors thank all participants in the cohort and the staff of Department of Obstetrics and Gynaecology in Kuopio University Hospital for skilful collection of study material.

\section{Funding}

This work was supported by the Research Committee of the Kuopio University Hospital Catchment Area for the State Research Funding and grants from Paulo Foundation, the Finnish Medical Foundation, the Paediatric Research Foundation, the Emil Aaltonen Foundation, University of Eastern Finland and National Institute of Health and Welfare.

\section{Authors' contributions}

$P H, L K N, S H, S V$, TPT, JP, JL, SML, HH, APE, RV, KB, HK, KK, JP, KV, MP wrote the paper with other authors. $\mathrm{PH}, \mathrm{HH}, \mathrm{MP}$ and JP are responsible for the metabolism and omics work package of KuBiCo. LKN and SH are responsible for the prenatal period and delivery work package of KuBiCo. SV and TPT are responsible for the nutrition work package of KuBiCo. JP and JL are responsible for the environment work package of KuBiCo. SML, APE and KK are responsible for the mental wellbeing work package of KuBiCo. RV and KB are responsible for the paediatrics work package of KuBiCo. HK is responsible for the analgesics and anaesthetics during peripartum period work package of KuBiCo. KV is responsible for the research ethics work package of KuBiCo. All authors read and approved the final manuscript.

Ethics approval and consent to participate

The Research Ethics Committee of Hospital District of Central Finland, Jyväskylä, Finland has reviewed and approved the KuBiCo protocol (dated 15.11.2011). Each participant signs an informed consent for KuBiCo. 


\section{Consent for publication}

Not applicable.

\section{Competing interests}

Authors declare that they do not have any commercial or financial competing interests.

\section{Publisher's Note}

Springer Nature remains neutral with regard to jurisdictional claims in published maps and institutional affiliations.

\section{Author details}

${ }^{1}$ School of Pharmacy, Faculty of Health Sciences, University of Eastern Finland, P.O. Box 1627, FI-70211 Kuopio, Finland. ${ }^{2}$ Department of Obstetrics and Gynaecology, Kuopio University Hospital, Fl-70211 Kuopio, Finland. ${ }^{3}$ Obstetrics and Gynaecology, University of Helsinki and Helsinki University Hospital, Fl-00029 Helsinki, Finland. ${ }^{4}$ Institute of Public Health and Clinical Nutrition, Faculty of Health Sciences, University of Eastern Finland, Fl-70211 Kuopio, Finland. ${ }^{5}$ Department of Public Health, University of Helsinki, Fl-00014 Helsinki, Finland. ${ }^{6}$ Department of Health Protection, National Institute for Health and Welfare, Fl-70210 Kuopio, Finland. ${ }^{7}$ Department of Psychiatry, Institute of Clinical Medicine, University of Eastern Finland and Kuopio University Hospital, Fl-70211 Kuopio, Finland. ${ }^{8}$ Institute of Behavioural Sciences, University of Helsinki, Fl-00014 Helsinki, Finland. ${ }^{9}$ Department of Neurosurgery, Institute of Clinical Medicine, University of Eastern Finland and Kuopio University Hospital, Fl-70211 Kuopio, Finland. ${ }^{10}$ Department of Paediatrics, Kuopio University Hospital, FI-70211 Kuopio, Finland. ${ }^{11}$ Department of Anaesthesia and Operative Services, Kuopio University Hospital and Institute of Clinical Medicine, University of Eastern Finland, Fl-70211 Kuopio, Finland. ${ }^{12}$ Department of Child Psychiatry, Institute of Clinical Medicine, University of Eastern Finland and Kuopio University Hospital, Fl-70211 Kuopio, Finland. ${ }^{13}$ Department of Biomedicine, University of Eastern Finland and Kuopio University Hospital, Fl-70211 Kuopio, Finland.

Received: 15 June 2017 Accepted: 13 September 2018

Published online: 21 September 2018

\section{References}

1. Hartwig I, Diemert A, Tolosa E, Hecher K, Arck P. Babies galore; or recent findings and future perspectives of pregnancy cohorts with a focus on immunity. J Reprod Immunol. 2015;108:6-11.

2. Piler P, Kandrnal V, Bláha L. Critical assessment of the research outcomes of European birth cohorts: linking environmental factors with noncommunicable diseases. Public Health 2017;145:136-45.

3. Ries NM, LeGrandeur J, Caulfield T. Handling ethical, legal and social issues in birth cohort studies involving genetic research: responses from studies in six countries. BMC Med Ethics. 2010;11:4.

4. Anderson LM, Diwan BA, Fear NT, Roman E. Critical windows of exposure for children's health: cancer in human epidemiological studies and neoplasms in experimental animal models. Environ Health Perspect. 2000;108(Suppl 3):573-94.

5. Prusinski L, Al-Hendy A, Yang Q. Developmental exposure to endocrine disrupting chemicals alters the epigenome: identification of reprogrammed targets. Gynecol Obstet Res. 2016;3:1-6.

6. Huuskonen P, Storvik M, Reinisalo M, Honkakoski P, Rysa J, Hakkola J, et al. Microarray analysis of the global alterations in the gene expression in the placentas from cigarette-smoking mothers. Clin Pharmacol Ther. 2008;83:542-50.

7. Huuskonen $P$, Amezaga M, Bellingham M, Jones L, Storvik M, Häkkinen M, et al. The human placental proteome is affected by maternal smoking. Reprod Toxicol. 2016;63:22-31.

8. Storvik M, Huuskonen P, Pehkonen P, Pasanen M. The unique characteristics of metabolism enzymes in placenta. Reprod Toxicol. 2014;47:9-14.

9. Dennedy MC, Dunne F. The maternal and fetal impacts of obesity and gestational diabetes on pregnancy outcome. Best Pract Res Clin Endocrinol Metab. 2010;24:573-89.

10. Birnbaum LS, Fenton SE. Cancer and developmental exposure to endocrine disruptors. Environ Health Perspect. 2003;111:389-94.

11. Azad MB, Moyce BL, Guillemette L, Pascoe CD, Wicklow B, McGavock JM, et al. Diabetes in pregnancy and lung health in offspring: developmental origins of respiratory disease. Paediatr Respir Rev. 2017;21:19-26.
12. Glass S, Phan A, Williams JN, Flowers CR, Koff JL. Integrating understanding of epidemiology and genomics in B-cell non-Hodgkin lymphoma as a pathway to novel management strategies. Discov Med. 2016;21:181-8.

13. Xie $P$, Zang LQ, Li XK, Shu Q. An epigenetic view of developmental diseases: new targets, new therapies. World J Pediatr. 2016;12:291-7.

14. Lahesmaa-Korpinen A, Artama M, Gissler M, Heino A, Malm H, Ritvanen A, Expert group. Maternal medicine use during pregnancy, risks for perinatal health and major congenital anomalies 1996-2010. Report 20/2014. Helsinki: National Institute for health and welfare (THL); 2014. http://urn.fi/URN:ISBN: 978-952-302-199-0. Accessed 12 June 2017

15. Liang B, Li L, Tang LY, Wu Q, Wu XK, Wang CC. Safety of Chinese herbal medicines during pregnancy. J Appl Toxicol. 2015;35:447-58.

16. Vuori E, Gissler M. Perinatal statistics - parturients, deliveries and newborns 2015. In: Statistical report 16/2016. Helsinki: The National Institute for health and welfare (THL). http://urn.fi/URN:NBN:fi-fe2016101024921. Accessed 12 June 2017.

17. The National Institute for Health and Welfare (THL) and the National Nutrition Council Eating together - food recommendations for families with children, 2016. http://urn.fi/URN:ISBN:978-952-302-599-8. Accessed 12 June 2017.

18. Rinaudo P, Wang E. Fetal programming and metabolic syndrome. Annu Rev Physiol. 2012;74:107-30.

19. Vähäkangas K. Chemical exposure as etiology in developmental origin of adult onset human cancer. Front Pharmacol. 2011;2:62.

20. Birnbaum LS, Miller MF. Prenatal programming and toxicity (PPTOX) introduction. Endocrinology. 2015;156:3405-7.

21. Cox JL, Sagovsky R, Holden JM. Detection of postnatal depression development of the 10-item Edinburgh postnatal depression scale. Br J Psychiatry. 1987;150:782-6.

22. Heino A, Gissler M. Perinatal statistics in the Nordic countries 2014. In: Statistical report 2016. Helsinki: The National Institute for Health and Welfare (THL). http://urn.fi/URN:NBN:fi-fe201603148739. Accessed 12 June 2017.

23. Heino A, Gissler M, Hindori-Mohangoo AD, Blondel B, Klungsøyr K, Verdenik I, et al. Euro-Peristat scientific committee. Variations in multiple birth rates and impact on perinatal outcomes in Europe. PLoS One. 2016;e0149252:11.

24. Gutierrez-Adan A, Pintado B, de la Fuente J. Demographic and behavioral determinants of the reduction of male-to-female birth ratio in Spain from 1981 to 1997. Hum Biol. 2000;72:891-8.

25. Macdonald-Wallis C, Tilling K, Fraser A, Nelson SM, Lawlor DA. Associations of blood pressure change in pregnancy with fetal growth and gestational age at delivery: findings from a prospective cohort. Hypertension. 2014;64:36-44.

26. Davis DL, Webster P, Stainthorpe H, Chilton J, Jones L, Doi R. Declines in sex ratio at birth and fetal deaths in Japan, and in U.S. whites but not African Americans. Environ Health Perspect. 2007;115:941-6.

27. Eke AC, Saccone G, Berghella V. Selective serotonin reuptake inhibitor (SSRI) use during pregnancy and risk of preterm birth: a systematic review and meta-analysis. BJOG. 2016;123:1900-7.

Ready to submit your research? Choose BMC and benefit from:

- fast, convenient online submission

- thorough peer review by experienced researchers in your field

- rapid publication on acceptance

- support for research data, including large and complex data types

- gold Open Access which fosters wider collaboration and increased citations

- maximum visibility for your research: over $100 \mathrm{M}$ website views per year

At BMC, research is always in progress.

Learn more biomedcentral.com/submissions 